\title{
Juan Martín Cordero en Flandes: Humanismo, mecenazgo e imprenta*
}

\author{
Juan Martín Cordero in Flanders: \\ Humanism, patronage and printing
}

Josep Lluís Martos

Universitat d'Alacant

RESUMEN: El humanista valenciano Juan Martín Cordero estuvo en Flandes durante la estancia de Felipe II y su corte entre 1555 y 1559. Allí interactuó con nobles, secretarios reales, humanistas, comerciantes e impresores; sin embargo, teníamos muy pocos datos sobre esto y, en muchos casos, eran contradictorios. Este trabajo delimita y estudia la figura de Cordero en Flandes a través de sus memorias y de las ediciones de sus obras.

Palabras clave: Juan Martín Cordero, Flandes, Humanismo, mecenazgo, imprenta, corte.

ABSTRACT: The Valencian humanist Juan Martín Cordero was in Flanders during the visit of Philip II and his court between 1555 and 1559. There interacted with noble, royal secretaries, humanists, merchants and printers, but we had very little data on this and in many cases were contradictory. This work defines and explores the figure of Cordero in Flanders through his memories and the editions of his works.

Keywords: Juan Martín Cordero, Flanders, Humanism, patronage, printing, court.

* Este trabajo se enmarca dentro del proyecto Cancionero, romancero e imprenta, financiado por el Ministerio de Economía y Competitividad (FFI2014-52266), del cual soy investigador principal. 
Tres años antes de llevar a la imprenta el Cancionero general de 1557 [ $\mathrm{n}^{\circ}$ $175]^{1}$, el humanista valenciano Juan Martín Cordero y Olivar entró en contacto con su impresor, Martín Nucio, hecho que Peeters Fontainas interpreta que "sans doute est-ce lui qui mit la dernière main à tant d'éditions célèbres sorties de l'officine de Nutius, le Cancionero de romances, le Cancionero general de 1557" (1953: 59-60). Rodríguez-Moñino (1965: XVIII) considera factible esta hipótesis implícitamente en su introducción al diccionario de impresiones hispano-flamencas de Peeters Fontainas (1965) y, explícitamente, en su edición del Cancionero de romances de 1550, cuando habla del proceso de transcripción, composición y revisión de éste ${ }^{2}$ : ¿¿No podría pensarse en Juan Martín Cordero, humanista, traductor y editor español para Nucio? Peeters Fontainas ha sospechado agudamente su intervención en el Cancionero general (1557) o en los Lazarillo de Tormes que salieron de su casa. Sería cosa de plantear en serio esta labor" (Rodríguez-Moñino, 1967: 12, n. 10). Joaquín González Cuenca, a partir de esta bibliografía y a pesar de reclamar Rodríguez-Moñino una investigación mayor, concluye que "se está asentando la convicción de que debajo de la edición del Cancionero está el andariego humanista valenciano" (González Cuenca, 2004, I: 74), una convicción con pocos fundamentos, ya que los datos sobre la estancia de Cordero en Flandes son escasos e interpretados parcial o incorrectamente. Precisamente por esto, el objetivo principal de este trabajo es la reconstrucción del periplo flamenco de este humanista español y su relación allí con la imprenta, que pueda servir de referente para una figura prácticamente desconocida y, sin embargo, clave desde diferentes líneas de estudio.

Son dos las fuentes principales que relacionan a Martín Nucio con Juan Martín Cordero: las Memorias o Autobiografía de éste último (Martí Grajales, 1927: $\left.128-168^{3}\right)$, "escritas sin ninguna pretensión, únicamente para sus sobrinos" ha-

${ }^{1}$ La primera vez que haga referencia a algún impreso hispano-flamenco, indicaré entre corchetes el número que recibe en el catálogo de Jean F. Peeters Fontainas (1965), sin repetir innecesariamente la referencia bibliográfica.

2 "Poco trabajo cuesta imaginar a Nucio —o a quien encargase de la tarea — tomando nota de los textos dictados por algún soldado extremeño, castellano, andaluz o manchego" (RodríguezMoñino, 1967: 12).

${ }^{3}$ La Biblioteca Valenciana, en la revista en línea Métodos de Información (julio de 2000), anunció: "Se prevé, para final de año, la publicación del Testamento y Autobiografía de Juan Martín Cordero y Olivar, humanista valenciano, burgués, de origen converso, estudiante en Lovaina, traductor, corrector de pruebas y gran viajero. El texto manuscrito del siglo XVI de esta Autobiografía se encuentra en el fondo bibliográfico Nicolau Primitiu conservado en la Biblioteca Valenciana. La edición estará al cuidado de dos especialistas en la obra de Cordero y Olivar, los profesores Miquel Almenara y Matías Barchino" < http://www.avei.org/revista/mei38/2000-38-05.pdf> [Fecha de consulta 26-04-2009]. Se preveía la publicación de esta edición dentro de la "Col·lección Humaniora", coeditada por la Biblioteca Valenciana y la Editorial Pre-Textos, pero parece que nunca ha visto la luz, como se desprende de las diferentes búsquedas que he realizado y de mis consultas en la web oficial del ISBN español. La única edición de la Autobiografía de Cordero sigue 
cia 1588 (Groult, 1958: $3^{4}$ ), y el rastro que deja en algunas ediciones su colaboración con Nucio y otros impresores. Más allá del valor literario de las $M e$ morias de Juan Martín Cordero, destaca su carácter precursor en cuanto al género de memorias profano, como ha insinuado Pierre Groult (1958: 3): “НHay muchas memorias en España antes de Cordero?'. No siempre podemos utilizar estas memorias, sin embargo, como fuente documental estricta, porque en ocasiones no es fácil fijar una cronología de los hechos, sobre todo cuando se refiere a la duración de las diferentes estancias en uno u otro lugar. Valga como ejemplo, precisamente, la datación del episodio en que narra su colaboración con Nucio, un documento en que se funda la hipótesis de Peeters Fontainas:

De alli [de Lovaina] por falta de dinero torneme a Anuers, y fuy muy rogado por Martin Nucio que a requesta de unos señores mercaderes traduxesse el duello de Alciato, en castellana lengua y lo hize assí, y lo dedique a don Hernando de Gonzaga general del Emperador; después muy rogado tome assiento en casa de Martin Nucio impresor de libros, para corregir sus impresiones, y traduxe las Flores de Seneca que imprimio mi amigo christoual Plantino, y fue el primer libro que el imprimio en Anuers, y estando en casa del Nuncio traduxe nueuamente al Josefo de Bello Judaico, y lo dediqué al Rey nro. S. ${ }^{\text {r. }}$. Y otro libro llamado declaración de la muerte y otras cosas en que puse la manera de bien escreuir en castellano. Traduxe tambien el Eutropio, y traduxe tambien el promptuario de las medallas los quales se imprimiern en lion de francia, por guillermo Ronillio de los mas polidos impressores de lion. Y a requesta de un curioso aleman llamado Huberto Golthzio traduxe tambien las medallas y vidas de todos los emperadores, en forma de pliego, y despues traduxe una doctrina christiana la qual hize despues añadida imprimir en Valencia, y fue impresa en Anuers y en Castilla, y la dirigí al duque de sesa con (quien) tuue estrecha amistad en flandes, hombre de gran juizio, y de partes para Principe muy señaladas, y muy heroicas, este fue nieto del gran capitan gonzalo fernandez (Martí Grajales, 1927: 147-148).

De manera paralela, Cordero nos informa también en sus Memorias de que, desde Inglaterra, tras asistir a la boda del príncipe Felipe y María Tudor, en la

vispera de la bendita S. ${ }^{\text {ta }}$ Catharina llegamos a Anuers. Y como antes de la partida uuiese tomado 30 escudos a cambio para la jornada, como llegue alli halle otros treynta que mi padre me auia embiado, y assi estuve alli unos pocos dias, y torneme a louayna, aunque unos caualleros que importunauan me quedase alli, y estuueme otros dos años estudiando mis estudios, y otro buenas letras, porque estas jamas las oluide ni las oluidare hasta la sepultura (Martí Grajales, 1927: 147).

siendo, por lo tanto, la de Francisco Martí Grajales (1927). Peeters Fontainas (1953) traduce al francés algunos extractos y aporta la ficha bibliográfica de las diez ediciones de obras traducidas por Cordero e impresas en Flandes.

${ }^{4}$ Véase también Pierre Groult (1962). 
Por lo tanto, si, según estas memorias, Juan Martín Cordero había llegado a Amberes el 18 de noviembre de 1554 y sólo estuvo allí unos días, hasta que regresó a Lovaina para continuar sus estudios durante dos años antes de volver a trabajar por falta de dinero, Cordero no habría colaborado con el taller de Martín Nucio hasta finales de 1556, como muy pronto, y esto no fue asís.

Aunque se hayan producido alteraciones derivadas de las características del género de memorias, cuyas ambigüedades temporales al referirse a períodos de tiempo no delimitados por fechas concretas no permiten siempre la posibilidad de establecer una cronología exacta de la estancia de Cordero en Flandes, no podemos rechazar sistemáticamente la información aportada por el valenciano, por considerarla inexacta. Su Autobiografía no puede deformar, por ejemplo, la causa por la que había entrado en contacto con Nucio y el inicio de su colaboración con éste. Antes de viajar a Inglaterra y sabiendo ya de la futura boda de Felipe y María Tudor, o sea, en el primer semestre de 1554, marcha a Amberes para imprimir su traducción de la Cristiada, de Jerónimo Vida [n 1372], con intención de dedicarla a la reina María de Inglaterra y llevársela como presente. Esto lo hace en el taller de Martín Nucio ${ }^{6}$, con el que debió de entrar en contacto por primera vez en este momento, como cree también Peeters Fontainas (1953: 59). De hecho, la supuesta colaboración entre ambos en el Cancionero de romances es una hipótesis imposible, ya que Cordero comenzó su viaje europeo el 20 de agosto de 1550 — con dieciocho años — llegó a París el 24 de septiembre de ese mismo $a_{\text {ño }}^{8}$ y estaba todavía en prisión el 20 de diciembre de $1552^{9}$. No sabemos la duración de su encarcelamiento, descrito, sin embar-

\footnotetext{
${ }^{5}$ Las idas y venidas de Lovaina a Amberes son lógicas, porque son "dos importantes centros internacionales, el uno por su Universidad, el otro por su comercio, cierto, pero también por sus imprentas y por el movimiento intelectual y artístico que florecía en su seno, y en el que los españoles desempeñan un papel considerable" (Groult, 1958: 2). Aunque sin aportar ningún caso de incoherencia cronológica, comparto con Groult (ibíd.) la dificultad para "determinar con certeza cuándo Cordero vivió en una y otra de aquellas ciudades. Sus Memorias, que agrupan de buena gana hechos cronológicamente separados, no nos proporcionan datos precisos sobre el asunto".

6 "En este tiempo auiendo començado en Paris el tiempo que estuue cerrado alli mi carcel y libertad de traduzir la Christiada de Vida, y a mis horas entendiesse en acabar estos libros, los acabe aunque los traduxe tan a la letra que no deuiera, porque por esto me lo prohibieron, siguiendo yo la poesia y frases del dicho Jeronimo Vida. Vineme a Anuers a imprimirlo, y me concerte con el librero, y habilite en el negocio y arte de imprimir quanto otro ninguno" (Martí Grajales, 1927: 144).

7 "Naci dia de S. Martin a las quatro horas de la madrugada a los onze de Nouiembre año 1531 quando mis padres auian venido de Liria adonde se auian antes retirado, por las muertes grandes que auia auido en Valencia" (Martí Grajales, 1927: 128-129); "y a los 20 de agosto de dicho año 1550 partimos de Valencia” (Martí Grajales, 1927: 130).

8 "Llegamos por nras jornadas a París A los 24 de S. bre 1550 auiéndonos tardado en el camino deste los 20 de agosto que salidos de Valencia 34 jornadas" (Martí Grajales, 1927: 134).

9 "Y estuuimos desde el dia de la prision hasta el domingo antes de nauidad que aquel año fue en viernes, año 1552 antes de pascua como cuentan alla” ibíd.).
} 
go, con mucho detalle en sus Memorias (Martí Grajales, 1927: 133-141), aunque hay que suponer que, como muy pronto, hasta avanzado el año de 1553 no abandonó la prisión y, después de alguna otra peripecia, llegó a Flandes, a Lovaina, donde residió desde entonces (Bonilla y San Martín, 1907: 502) hasta su marcha a Amberes en el primer semestre de 1554. Con estos datos, sería un despropósito sostener la participación de Cordero en la editio princeps del Cancionero de romances de $1547-1548^{10} \mathrm{ni}$ en su reelaboración de 1550 , mientras que en la reedición de 1555, que sigue fielmente la anterior, ya no habría tenido ningún sentido, más allá de un trabajo técnico como corrector de imprenta.

Martín Nucio, que conocía de primera mano el ejercicio traductor de Cordero, le ofrece trasladar del latín al castellano las reglas del duelo codificadas por Andrea Alciato, que edita como De la manera de desafío en 1555 [n $\left.{ }^{\circ} 28\right]^{11}$. Parece que es a través de este encargo cuando se incorporó a la "casa de Martin Nucio impresor de libros, para corregir sus impresiones" (Martí Grajales, 1927: 147-148). Esta colaboración fue muy intensa en 1555 y 1556, como se documenta a través de la fecha de varios impresos que Cordero tradujo para Martín Nucio. Además de la Cristiada y De la manera de desafío, tenemos constancia explícita de esta colaboración en otras dos ediciones: la traducción de Las quexas y llanto de Pompeyo en 1556 [n $\left.\mathrm{n}^{\circ} 274\right]$ y la del De bello judaico de Flavio Josefo en 1557 [ $\mathrm{n}^{\mathrm{o}} 637^{12}$ ].

Las quexas y llanto de Pompeyo es la primera obra de un volumen facticio, que significa, sin duda, el principal argumento para incluir a Juan Martín Cordero entre los erasmistas españoles ${ }^{13}$, fiel a las inclinaciones humanistas de su

\footnotetext{
${ }^{10}$ Aunque esta obra no incluye el año de impresión, Jean F. Peeters Fontainas (1965: 20-21) lo establece "tras un detenido estudio del escudete que figura en el volumen, deduce con buenos argumentos que puede señalarse como salido entre 1547 y 1548 . Básase para ello en que tal marca tiene un defecto, el cual aparece por vez primera en 1546 en la edición de la Qüestion de amor, mientras que en las Meditationes de San Agustín (1550) ya tiene tres. Como de 1550 es también la segunda edición del Cancionero hay que suponer que la primera apareciese aproximadamente un año o año y medio antes. Otras razones de tipo literario hay que sospechar que no debió de ser de 1546, entre ellas la utilización en esa fecha de un pliego suelto con texto inferior al que figura en el Cancionero" (Rodríguez-Moñino, 1967: 11).

${ }^{11}$ Según determina Peeters Fontainas (1965: 17), porque no tiene pie de imprenta. Esta obra es reeditada en las prensas de su hijo Martín en 1595 [ $\mathrm{n}^{\circ}$ 29], probablemente, muerto ya Felipe, cuya última edición es de 1581; la primera del hijo homónimo de Martín Nucio es de 1586. Para las fechas en que los herederos de Martín Nucio se ocuparon de la oficina nuciana y las obras que imprimieron, remito al catálogo de Peeters Fontainas.

${ }^{12} \mathrm{El}$ impresor ya había publicado la traducción de esta obra en $1551\left[\mathrm{n}^{\circ} 635\right]$ y en $1554\left[\mathrm{n}^{\circ}\right.$ 636]. Sólo la edición de 1557 es una traducción de Cordero, como Martín Nucio explicita en la portada, a diferencia de los otros dos impresos anteriores: "traduzidos agora nuevamente según la verdad de la historia por Juan Martin Cordero". No debieron de convencer mucho a Nucio las diferentes traducciones de 1551 y de 1554 y, conociendo bien la calidad traductora del humanista valenciano, le encargó esta empresa.

${ }^{13}$ Lo considera erasmista Bonilla y San Martín (1907: 500-506) y así lo aceptan Marcel Bataillon (1966: 719, n. 16) y, recientemente, José Luis Gonzalo Sánchez-Molero (1997: 695).
} 
tío materno, Pere Joan Olivar, que por aquellas mismas épocas se encontraba en Flandes y con quien había mantenido un contacto escrito relativamente frecuente $^{14}$. Describe muy bien el volumen ya Bonilla y San Martín (1907: 500502) y, después, lo hará Peeters Fontainas (1953: 80, 150-151 y 1965: 73-74) en su traducción de un extracto de las memorias de Cordero, en su monográfico sobre el taller de Martín Nucio y en su catálogo de impresiones hispano-flamencas $^{15}$. De la obra que da título al volumen — Las quexas y llanto de Pompeyo sobre la destrución de la República Romana (ff. 2r-34v)—,

indica Cordero que se trata de una traducción, pero calla el nombre del autor, razón por la cual, y por la relativa rareza del opúsculo, ha pasado inadvertido. Ahora bien, leído el último, no me cabe duda de que se trata de una versión de la declamación de Juan Luis Vives rotulada: Pompeius fugiens, primera muestra de los trabajos retóricos del insigne humanista valenciano (Bonilla y San Martín, 1907: 501).

Además de la Muerte atroz que el turco Solimán dio a un hijo suyo (ff. 35r$67 \mathrm{v}$ ) y del tratado sobre La manera de escrevir en castellano, o para corregir los errores generales en que todos casi yerran (ff. 107r-124v), esta recopilación impresa de obras de Cordero incluye la traducción de dos textos de Erasmo de Rotterdam ${ }^{16}$ : la Declamación de la muerte por consolación de un amigo (ff. 68r-86v) y la Exhortación a la virtud (ff. 87r-106v). Aunque no en las prensas de Nucio, sino en las de Cristóbal Plantino, publicó la traducción de las Flores de Séneca ${ }^{17}$, cuyo interés por parte de Cordero podría relacionarse

\footnotetext{
${ }^{14}$ Incluso, llegó a verlo antes de su visita a Inglaterra, encuentro en el cual Pere Joan Olivar dio unas cartas a su sobrino para sus colegas en Inglaterra: "Y como determinasse yr a Inglaterra adonde avia estado mucho tiempo el doctor Oliuario, tio mio no quise partir para alla sin lleuar algunas cartas suyas para ynglaterra, pes el tenia muchas amistades por alla donde auia estado algunos años, y teniendo en nueua que estaua en Lieja con el obispo que era entonces don Jorge de Austria, que era Arçobispo de Valencia, tome de Anuers la posta para alla, y como fuy en Lieja, dexaronme en palacio, que el dia antes se auia ydo a Coranja, casa de plazer y regalo del obispo, y luego al otro dia que llegue tome el camino para alla, y en llegar me dixeron que auia partido para louayna [...]. Luego tome el camino para louayna, por verlo y hablarle, porque aunque estando en colonia y en Paris nos auiamos escrito muchas uezes, todauia no lo auia visto en mi vida. Y lo halle alli, y holgamos una noche con otros amigos, y en la mañana el escriuio, y assi despedido que me uue me parti para Anuers" (Martí Grajales, 1927: 135).

15 Se conservan dos ejemplares en la Biblioteca Nacional de Madrid, con la signatura R-9190 y U-10396. Este último, que perteneció a Luis Usoz, está "encuadernado con la Institucion de un rey christano, por el Maestro Felipe de la Torre (Anvers, Martin Nucio, 1556)" (Bonilla y San Martín, 1907: 502).

16 "Se trata de la Declamatio de morte, dedicada a Glareanus (Allen, t. III, Ep. 604), y de la Oratio de virtute amplectenda, dedicada a Adolfo de Veere (Allen, t. I, Ep. 93)" (Bataillon, 1966: 719, n. 16).

${ }^{17}$ Nos informa de ello, de hecho, en sus memorias: "y traduxe las Flores de Seneca que imprimio mi amigo christoual Plantino, y fue el primer libro que el imprimio en Anuers" (Martí
} 
con traducciones de clásicos como la de Flavio Josefo o la de Eutropio y, así, pasar desapercibidos los tintes erasmistas del proyecto ${ }^{18}$.

Aunque Pierre Groult y su discípula Kerremans revisaron a fondo los archivos de la Universidad de Lovaina en busca de documentación sobre Cordero, sólo pudieron confirmar que "en el siglo XVI, las matrículas eran algo descuidadas, y si los registros de las cuentas eran mejor llevados, la casualidad quiere que no los tengamos ya desde 1557 hasta los principios del siglo siguiente. En todo caso, no hallamos huella alguna de nuestro joven estudiante" (Groult, 1958: 2). La pérdida de documentación desde 1557 hasta final de siglo los lleva a considerar que "es de 1556 a 1558 cuando Cordero estudió el derecho en Lovaina. Pasaría allí también algunos meses del año 53-54 y del año 54-55" (Groult, 1958: 2) y esto parecería confirmar la hipótesis de Marcel Bataillon (1966: 719, n. 16), que cree que Cordero

se encontraba sin duda en Lovaina cuando publicó este volumen [el facticio erasmista, $\mathrm{n}^{\circ}$ 274] y toda una serie de traducciones más (véase la Suma de doctrina cristiana), traducción del catecismo del Emperador Fernando, con una dedicatoria al Duque de Sessa, Conde de Cabra, Don Gonzalo de Córdoba, fechada "desta Universidad de Lovaina", a 15 de mayo de 1558.

Estos datos, sin embargo, no son estrictamente correctos en el caso de Groult y Kerremans y son equivocados en la hipótesis de Bataillon, que, injustificadamente, relaciona el volumen erasmista con otra obra que sí que se tradujo en Lovaina en 1558.

Hay un dato que me parece evidente y que tiene un peso importante en mi argumentación: la inmediatez de buena parte de las ediciones de $\mathrm{Nucio}^{19}$, que

Grajales, 1927: 147-148). Leon Voet, que publicó un espléndido trabajo sobre la imprenta de PlatinMoretus, estudió el privilegio imperial para ésta y otras ediciones de Plantin, en el que aparecía en segundo lugar, tras las Institutione de Brutto. Como considera que, sensu stricto, la traducción de Cordero no es la primera, sino la segunda obra impresa por Plantino en Amberes, interpreta la referencia de las Memorias de la siguiente manera: “Cordero's statement can perhaps be taken to mean that although the Institutione was the first book Plantin printed, it was actually published by Bellerus, and the Flores was Plantin's first publication and the first book to carry his printer's mark. (In fact, Cordero was wrong in stating that Plantin printed the Flores; according to the type used the work was done by another printer). The two statements together make it more than likely that Plantin's career as printer and publisher began with these two works" (Voet, 1969-1972: 17).

18 "Entre los antíguos está también su compatriota Séneca. Ya antes había deseado Erasmo verlo editado por un español. Cordero realizó pues, en parte, el deseo del grande humanista que él mismo se había encargado de proporcionar una buena edición y, después, una antología de dicho autor: esas Flores de Séneca las tradujo Cordero" (Groult, 1958: 2).

${ }^{19}$ Pensemos, por ejemplo, que cuando Cordero imprime la Cristiada, ya sabe que María Tudor será la nueva esposa del príncipe Felipe, de lo que no se sabía nada antes de diciembre de 1553. En este tiempo, llegan las noticias a Flandes — pensemos que Felipe II tardó tres meses en enterarse de la muerte de Carlos $\mathrm{V}$ - , Cordero marcha de Lovaina a Amberes, el libro sale a la calle y antes de julio de 1554 está en Inglaterra, esperando la llegada de príncipe Felipe, para casarse. 
está en relación directa con su prolijidad y que, en la mayoría de casos, permite establecer una casi identificación cronológica entre el trabajo de corrector o traductor y su impresión. Esto no ocurre así con otros impresores, pero sí con Juan Steelsio y Martín Nucio, cuya competitividad es paradigmática para entender el mercado editorial hispano-flamenco ${ }^{20}$. Si esto es así, tenemos algunos datos fehacientes a partir de sus impresiones que, puestos en paralelo con las memorias de Cordero, nos confirman, con bastante seguridad, unas premisas, cuyo estudio desarrollaré a manera de amplias conclusiones.

1. La traducción que hace Cordero del De bello judaico de Flavio Josefo para Nucio no sale a la luz en Amberes hasta 1557 y me inclino a pensar que, como en el resto de ocasiones, él estuvo por entonces todavía en aquella ciudad corrigiendo la edición. No debe interpretarse como un hecho fortuito la dedicatoria de esta obra a Felipe II, sino que alrededor del monarca se había ido estableciendo una notable actividad literaria que él mismo promovió:

La presencia de Calvete de Estrella, Laguna, Carranza, Pérez, Cordero, la Torre o Busto en torno al príncipe, y las obras que éstos publican o escriben, muchas de ellas dedicadas a Felipe II, dentro de lo que ha venido a denominarse como literatura erasmista, nos descubren con facilidad que el pensamiento de Erasmo pervivía en torno a la corte española (Gonzalo Sánchez-Molero, 1997: 697).

De hecho, estos mismos erasmistas filipinos están muy presentes en las prensas de Nucio y no debió de ser por casualidad. Ya con la visita del entonces príncipe Felipe a finales de $1548^{21}$, cuya estancia en Flandes duró hasta mayo de 1550, Nucio debió de entrar en contacto con la corte filipina o con el mismísimo príncipe, y se gestaron unas primeras ediciones como la traducción que hizo Bernardo Pérez de La lengua de Erasmo [ $\mathrm{n}^{\circ} 385$ ] en 1550, con privilegio imperial de hasta diez años, dato que puede ilustrar la posibilidad de que Nucio hubiese sido "visitado por Carlos V y por su hijo Felipe. Sus deseos o sus órdenes probablemente determinaron la impresión de ciertos volúmenes, que sin

20 "La rivalidad profesional entre dos grandes impresores antuerpienses del siglo XVI, ambos estampando textos españoles, Martín Nucio y Juan Stelssio, es verdaderamente curiosa. Los dos deseaban, sin duda, acaparar el mercado de lengua castellana y no daban paz a la mano en adquirir, arreglar a veces, y editar los volúmenes más deseados por el público. Si el privilegio real veda a uno de ellos difundir en sus talleres producciones que posee el otro, no vacila en buscar obras del mismo autor que se hallen libres. Casos hay en que toman traductores propios para idéntico libro, como los Apotegmas de Erasmo que dan al público ambos en el mismo año, uno según la versión de Francisco de Tamara y otro según la de Juan de Jarava" (Rodríguez-Moñino, 1967: 10-11).

${ }^{21}$ Para la importancia de las visitas de Felipe II en relación con las impresiones del taller de Nucio, véase Martos (2010a: 111-123). 
interés comercial, sólo es explicable por la presión política o el interés humanístico" (Gonzalo Sánchez-Molero, 1997: 69722). Con unas mismas motivaciones e intereses, Martín Nucio imprimió el 25 de mayo de 1552 El felicíssimo viaje del muy alto y muy poderoso príncipe don Phelippe, hijo del Emperador don Carlos Quinto Máximo, desde España a sus tierras de la baxa Alemaña, con la descripción de todos los estados de Brabante y Flandes, de Juan Cristóbal Calvete de Estrella [ $\mathrm{n}^{\circ}$ 170], "con gracia y privilegio de la Imperial Majestad para todos sus reynos, estados y señoríos, por quince años". Nucio no fue, sin embargo, el único impresor interesado en obras erasmistas, traducidas o producidas por estos humanistas cristianos deudores del mecenazgo de Felipe II y claramente relacionadas con la visita de éste a Flandes entre 1548 y 1550. Juan Steelsio [n ${ }^{\circ} 85,86,87,387$ y 603] y Juan Gravio [n ${ }^{\circ} 381$ y 383] también se unieron a los intereses por ese "mercado más rentable y directo, aunque temporal, como el que representaba el séquito español de don Felipe" (Gonzalo Sánchez-Molero, 1997: 695).

Con el regreso a Flandes de Felipe II y su corte en 1555, se reproduce este interés editorial por obras de erasmistas cercanos al monarca y Martín Nucio reedita en 1555 una obra de Erasmo, Preparación y aparejo para bien morir [ $\mathrm{n}^{\mathrm{o}} 382$ ], para la que tuvo privilegio imperial Juan Gravio en 1549 [ $\mathrm{n}^{\circ} 381$ ], ambas bajo la traducción de Bernardo Pérez. En ese mismo año, Nucio imprimió otra traducción de Erasmo, Silenos de Alcibiades [ ${ }^{\circ}$ 388], también de Pérez, lo que, unido a la impresión de 1550, parece evidenciar que fue este humanista el primer y principal contacto del impresor con la corte filipina. Después, vendrán otros, como Felipe de la Torre, a quien imprime en 1556 su Institución de un rey christiano [ $\mathrm{n}^{\circ}$ 680] o Bartolomé Carranza de Miranda, cuyos Comentarios sobre el Catechismo [ $\left.\mathrm{n}^{\circ} 191\right]$ saca de sus prensas en 1558. En ambos casos, se dedican las traducciones a Felipe II, algo que también hizo Juan Martín Cordero en 1557 en la edición tambien nuciana de Los siete libros de Flavio Josefo, los quales contienen las guerras de los judios y la destrucción de Hierusalem y del Templo.

En 1557, Juan Martín Cordero debía de ser considerado ya, efectivamente, como uno de los humanistas cristianos cercano a Felipe II y, al menos, ya debía de ser así en 1556, cuando salió de las prensas de Nucio su volumen facticio erasmista, dedicado a Gonzalo Pérez, secretario del monarca ${ }^{23}$. Sería un error interpretar que el humanismo de las primeras obras de Cordero que edita

\footnotetext{
${ }^{22}$ Estas presuntas visitas tienen que ver con la relación y patronazgo que ya desde los Reyes Católicos recibía la imprenta, con idea de apadrinar obras "algunos de cuyos autores se encuentran claramente vinculados a la corte" (Salvador Miguel, 2008: 235) y cuyos temas tenían relación directa con la difusión de la política y los ideales regios.

${ }^{23}$ Tal consideración se debió de derivar de la publicación de esta obra, que lo acabó consagrando dentro del grupo erasmista filipino en Flandes.
} 
Nucio en 1554 y 1555 responde exactamente a los mismos impulsos que su volumen de 1556. Es cierto que la Cristiada de Jerónimo Vida pretendía honrar al príncipe Felipe, pero también a la futura esposa, de la que destaca su genealogía española ${ }^{24}$. Sin embargo, el desconocimiento del rechazo de Felipe hacia la boda pactada por Carlos $\mathrm{V}$ y, por lo tanto, lo desgraciado de la unión, habla por sí mismo del carácter independiente e improvisado del pretendido elogio. Si buscó halagar, así, a Felipe, no debió de conseguirlo, independientemente de que valorara la calidad de su traducción, de la que, como a su esposa, le entregó un ejemplar ${ }^{25}$. Por otro lado, Cordero tradujo la obra De la manera de desafío de Alciato como encargo de Nucio, a petición de unos mercaderes ${ }^{26}$, un encargo profesional que no respondía necesariamente a intereses personales por la obra traducida, ni se puede relacionar con una voluntad de acercamiento o aceptación del círculo humanista del Príncipe, aunque sí del Emperador, a través de su general. Esto conduce a pensar que la gracia y el privilegio concedidos a la impresión fueron todavía entregados por Carlos V, lo que documenta la edición antes del 25 de octubre de 1555, fecha del relevo imperial.

El mercado editorial hispano-flamenco, en general, y, en particular, la edición de obras erasmistas se reactiva con la presencia y mecenazgo de Felipe y de algunos nobles de su corte. Nucio retoma sus contactos con los humanistas filipinos, a partir, probablemente, de Bernardo $\mathrm{Pérez}^{27} \mathrm{y}$, durante esa irrupción de erasmistas en sus prensas, Juan Martín Cordero estuvo allí, en el lugar y en el momento adecuado. Acababa de traducir para Nucio la obra de Alciato y es-

\footnotetext{
24 "Determinado de casar el principe don felipe que hoy es nro. Rey y señor con la Reyna Maria, como supiesse que auia de venir a Inglaterra, por ver las grandezas de aquel reyno, y ver tambien la corte de España que venia segun sabiamos por cartas ciertas, muy pomposa y con grandissimo fausto, y triunfo por acompañar al Principe, a una tierra que segun se sonaua estaua cargada de oro y riquezas, que les salio a todos muy al reves, determine dedicar mi libro a la Reyna de Inglaterra, llamada Maria, hija de la Reyna Catalina y del Rey Enrique, y nieta del valeroso y catholico Rey don fernando" (Martí Grajales, 1927: 144-145).

25 “Antes de despedirse, dixo el Embaxador Renarte a la Reyna: Señora reciba vra. Magestad este presente, y entonces yo arrodillado le di el libro, y ella para tomarle abaxo la cabeça y dixome en lengua francesa si era en Español, y yo respondi: Señora, si y que lo recibiesse en señal de mi vassallatge, y principio para la que esperaua de ofrecerle diziendo esto en frances assi como ella me hauia hablado" (Martí Grajales, 1927: 146). De hecho, más adelante y ya celebrada la boda, tuvo la oportunidad de ofrecer a Felipe otro ejemplar antes de regresar a Flandes: "Di tambien al Rey un libro de los mismos muy hermoso" (Martí Grajales, 1927: 147).

26 "Fuy muy rogado por Martin Nucio que a requesta de unos señores mercaderes traduxesse el duello de Alciato, en castellana lengua y lo hize assí, y lo dedique a don Hernando de Gonzaga general del Emperador" (Martí Grajales, 1927: 147).

${ }^{27}$ Había editado una traducción suya de Erasmo en 1550 y, de nuevo, lo hace en 1555, con otras dos obras: Preparación y aparejo para bien morir y Silenos de Alcibiades. Ésta es otra muestra evidente de la velocidad de funcionamiento que tenían las prensas de Nucio, ya que, en sólo cuatro meses, saca a la luz estos textos, con intención de aprovechar el mercado, en un principio fugaz, que suponía la visita de Felipe y su corte.
} 
tas nuevas circunstancias anunciaban unas perspectivas editoriales que requerían un perfil de corrector como el de Cordero. En el desarrollo de esta función, tuvo posibilidad de relacionarse más cercanamente con alguno de estos humanistas o con sus mecenas, e ir integrándose, así, en ese ambiente intelectual filipino. Unos meses después de ese contacto fue cuando imprimió un volumen decididamente erasmista, dedicado, como la traducción de Alciato, a un miembro de la corte del monarca: en este caso, a su secretario, Gonzalo Pérez ${ }^{28}$. La traducción de Flavio Josefo, impresa al año siguiente, se dirigió decididamente a Felipe II, sin cortesanos intermediarios en su búsqueda de mecenazgo, lo que podría dar muestra de su grado de integración en la corte y de su acercamiento —o voluntad de ello_- al mismísimo monarca.

2. Tenemos constancia fehaciente de que entre el 15 de mayo y el 8 de septiembre de 1558, Juan Martín Cordero estaba en la Universidad de Lovaina, porque así datan las dedicatorias de dos de sus traducciones: la Summa de la doctrina christiana de Canisio [ $\left.\mathrm{n}^{\circ} 181\right]$, salida en las prensas antuerpienses de Guillermo Simón, y la primera parte del Promptuario de medallas, editada en casa de Guillermo Rovillo o Bonilio en Lyon el 1561. La primera de éstas se dedica a Gonzalo Fernández de Córdoba, III Duque de $\mathrm{Sessa}^{29}$, que debió de ser el intermediario del encargo de la traducción de este catecismo, como lo llama Felipe II en la Carta y mandamiento impresa al inicio de la edición, para luchar contra el luteranismo con sus mismas armas y educar en el cristianismo

\footnotetext{
${ }^{28}$ A partir de este mismo año, la importancia de Gonzalo Pérez en la administración filipina cobró una importancia capital, sobre todo por lo que tocaba a Flandes: "Ya en 1556, entre las diversas medidas de reestructuración administrativa que llevó a cabo Felipe II en los inicios de su reinado, también las secretarías habían experimentado varias modificaciones. La secretaría de Estado, cuya titularidad permanecía vacante desde el fallecimiento de Francisco de los Cobos, fue desgajada siguiendo criterios territoriales, encargándose a Gonzalo Pérez el despacho de los negocios que se ofrecían fuera de la Península y a Juan Vázquez de Molina los que correspondieran a ella" (Carlos Morales, 1994a: 134).

29 "Traduxe una doctrina christiana la qual hize despues añadida imprimir en Valencia, y fue impresa en Anuers y en Castilla, y la dirigi al duque de sesa con (quien) tuue estrecha amistad en flandes, hombre de gran juizio, y de partes para Principe muy señaladas, y muy heroicas, este fue nieto del gran capitan gonzalo fernandez" (Martí Grajales, 1927: 148). Muerto ya Martín Nucio, la imprimió en el taller de Guillermo Simon. Esa estrecha amistad con el Duque de Sessa debió de haber sido una de las puertas de entrada a su relación con el Rey, como ocurrió más tarde con Melchor de Herrera, aunque con intereses diferentes, ya que dirigió la Tesorería General de Castilla desde septiembre de 1565. Sirvió al Duque de Sessa en Milán "capitaneando en 1559 una compañía de caballería ligera de 102 soldados" (Carlos Morales, 1994b: 382) y "avecindado de nuevo en Madrid, Melchor de Herrera buscó el favor de la facción que entonces controlaba los resortes del poder, el 'partido ebolista'. Quizá gracias a la recomendación del Duque de Sessa, a quien sirviera en Milán, pudo arrimarse y ganar la confianza del personaje que desde años antes se había convertido en privado de Felipe II, Ruy Gómez de Silva" (Carlos Morales, 1994b: 382).
} 
a sus súbditos desde la niñez ${ }^{30}$. La relación del Duque de Sessa con el monarca era muy estrecha, como demuestra la confianza de éste al nombrarlo gobernador de Milán por esas fechas ${ }^{31}$. De hecho, lo era ya cuando se acaba la traducción y se redacta la dedicatoria "Al illustríssimo y excelentíssimo señor don Gonçalo de Córdova, duque de Sesa, conde de Cabra, Governador del estado de Milán, lugarteniente y capitán general por su M. en Ytalia”, que es un panegírico del gusto y defensa de las letras por parte del Duque de $\mathrm{Sessa}^{32}$, en una línea parecida a la dedicatoria que le dirigió Juan de Resa en el cancionero de Ausiàs March impreso en Valladolid en 1555 (Escartí, 1997: 291-292).

Las relaciones de Juan Martín Cordero con los círculos más granados de la corte hispano-flamenca dieron lugar a una intensa actividad de mecenazgo alrededor de su persona, como se puede desprender de las dedicatorias de sus obras, cuyo estudio retomaré en otro contexto más adecuado ${ }^{33}$. Si bien Cordero dedicó obras a secretarios, funcionarios o nobles del entorno de los monarcas, también buscó el mecenazgo directo de la familia real: dirigió la Cristiada a María Tudor — cuando aún no conocía la desgana de Felipe por esta boda- con una voluntad clara de relacionarse con esa corte española que se iba a establecer en In-

30 "Y d'esto nos han dado los adversarios de nuestra religión en estos postreros años exemplo manifiesto (lo qual no podemos recontar sin dolor de nuestro coraçón). Los quales cierto está que siempre trabajaron mucho para engañar a la mocedad, que no es astuta ni fe sabe bien guardar de la hiel que está debaxo de la miel, con doctrinas bien compuestas y que son dadas por orden convenible de enseñar, que llamaron Cathecismos, captivando sus coraçones con diversos, nuevos y jamás oýdos tales libros y engañándolos con malas opiniones, las quales fuertemente enxeridas y después que ya han echado profundas raýzes, mal se pueden arrancar aún de los que ya son crecidos en edad. Por lo qual nos pareció ser cosa muy provechosa fortalecer los coraçones de nuestros vasallos y súbditos con un Cate $\left[\mathrm{aIII}^{\mathrm{v}}\right]$ chismo o instrucción contraria a la d'ellos, como con una medicina contra la ponçoña. Y como fuéssemos del todo deliberados de hazerlo assí y encommendássemos a algunos sabios theólogos que tomassen cargo d'este negocio, ellos affirmaron no se poder dar libro más a propósito ny más provechoso qu'el Catechismo de nuestro muy amado tío Ferdinando, Rey de los romanos, de Hungría y Boemia, al qual él, pocos años ha, propuso a los suyos, mandando por su autoridad que lo guardassen y siguiessen". La edición es mía.

31 "La renovación de personas y cuadros cortesanos fue seguida de cambios en los puestos de virreyes y gobernadores. Se produjo un desplazamiento de la elite hispano-italiana vinculada al 'clan Toledo' por un nuevo grupo todavía no bien definido que giraba en torno a Éboli. En 1558 se nombró como nuevo virrey de Nápoles a Perafán de Ribera, duque de Alcalá, amigo del Duque de Francavilla y del secretario Vargas. En 1557 fue cesado Juan de Vega como virrey de Sicilia — quien, precisamente, achacó este suceso a una intriga de Palacio—, ocupando su lugar un significado 'ebolista', el Duque de Medinaceli. Y, finalmente, también en 1558, don Gonzalo Fernández de Córdoba, duque de Sessa, fue nombrado gobernador de Milán, ebolista, según Marañón, por odio a la casa de Alba. Este último caso ejemplifica de forma notable este relevo de poder" (Rivero Rodríguez, 1994: 325).

${ }^{32}$ La esencia del elogio de Cordero se sintetiza muy bien en esta frase de la dedicatoria: "Una de las cosas mejores y que más ilustran las armas son las letras, de tal manera que un Capitán con letras en un día alcança más que otros sin ellas en ciento”.

${ }^{33}$ Nicasio Salvador Miguel (2008: 222) y Marina Núñez Bespalova (2008: 183) han justificado estos documentos como fuente para determinar el mecenazgo de Isabel I. 
glaterra y de la que, a sus escasos veintitrés años, esperaba recibir un patronazgo; dedicó a Felipe II su traducción del De bello judaico; y, finalmente, dirigió el Promptuario de medallas "al muy alto y muy poderoso señor don Carlos, por la gracia de Dios, Príncipe de las Españas", de nuevo, con idea de honrar al monarca ${ }^{34}$. Es lógico pensar que un humanista cristiano como lo fue Cordero no sólo recibió apoyos del monarca y de alguno de sus cortesanos, sino también de algún jerarca eclesiástico, que debía de llevar este tipo de actividades de manera anónima todavía, como ocurría en la corte de Isabel I (Herrán, 2008: 83), y por esta razón no tenemos constancia documental de ello; sin embargo, no tengo duda de que en Flandes uno de los principales mecenas eclesiásticos fue el poderoso Obispo de Arras, Antonio Perrenot de Granvela, que en 1561 es nombrado cardenal, entre 1571 y 1575 es virrey de Nápoles y es presidente del Consejo de Estado en 1579 en Italia y, entre 1580 y 1581 en España, durante la ausencia del monarca con motivo de la guerra contra los portugueses. Cordero no sólo conoció a Antonio Perrenot, sino que siguió de cerca su trayectoria desde Valencia, ${ }^{35}$ cuya muerte en 1586 fue muy cercana a la fecha de redacción de sus memorias (c. 1588), un óbito que causó gran "lastima de todos sus clientes y aliados y fauorecidos entre los quales fuy yo uno aunque indino, porque recebi del muchissimas mercedes" (Martí Grajales, 1927: 148). Entre estos clientes, aliados y favorecidos estuvo Cordero, como él mismo reconoce, y, en forma de mecenazgo, recibió del Obispo de Arras tales mercedes.

3. Por sus memorias, sabemos que el padre de Cordero le había recordado por carta que las razones de su viaje a los Países Bajos eran sus estudios, por

\footnotetext{
${ }^{34}$ Con posterioridad a esto, el príncipe Carlos, primogénito de Felipe II e hijo de María de Portugal, conspiró con los rebeldes flamencos contra su padre y, encerrado por éste último en el castillo de Arévalo, acabó muriendo en 1568. Hay la noticia de una posible edición de 1558 en Lovaina [ $\mathrm{n}^{\circ}$ 1144], pero es a través de un catálogo de libros vendidos en Amsterdam el 20 de febrero de 1724, que debió de silenciar una posible falta de portada de la edición. A partir de esto se tomó por buena la fecha del prefacio del traductor: "Faut-il maintenir ce titre parmi les impressions espagnoles del Pays-Bas? Nous en doutons; à l'origine, il y a incontestablement l'indication du catalogue des livres vendus à Amsterdam le 20 février 1724 (lot 152), mais à cette époque les catalogues étaient rédigés avec moins de scrupule et de soin qu'aujourd'hui, et n'indiquaient pas les défauts des lots exposés en vente. Il est plus que probable que le libraire offrait un exemplaire de l'édition de Lyon 1561, incomplet du titre, et qu'il aura de bonne foi, au vu de la dédicace de Cordero, attribué au volume l'adresse et la date de Louvain 1558. Aucun exemplaire n'est d'ailleurs connu, et Cordero lui-même imprimieur et éditeur, fasse imprimer à Louvain un ouvrage qui comprend principalement de nombreuses planches gravées sur bois, alors qu'il avait déja imprimé en 1553, trois éditions en latin, italien et français? Conçoit-on que l'édition espagnole, quì aurait paru fin 1558, soit épuisée, à peine trois ans après, et qu'il faille en donner une novelle édition en 1561?" (Peeters Fontainas, $1965: 583$, n. 1).

35 "Fue virrey de Napoles, gran presidente del consejo de Estado, y del de guerra, porque se auia hallado en muchas empresas el y acompañado al Emperador y después al Rey su hijo nro. S. or." (Martí Grajales, 1927: 148).
} 
lo que marchó a Lovaina y llegó a concluir dos cursos de leyes ${ }^{36}$. Más allá de las recomendaciones paternas, su marcha coincidió demasiado casualmente con el traslado de Felipe II a Inglaterra en marzo de 1557, cuya fecha de regreso —en julio de ese mismo año- no tenía por qué haber estado prevista ${ }^{37}$. Tras este viaje de Felipe y de lo más granado de su corte a Inglaterra, Cordero habría perdido una de las razones fundamentales para permanecer en Amberes y satisfizo sin mayor problema las recomendaciones de su padre. Probablemente, fue ésta una de las principales razones para el traslado de Cordero a Lovaina: la ausencia física de buena parte de sus mecenas, cuyos encargos, sin embargo, siguió realizando en Lovaina, como demuestra la traducción de la Summa de la doctrina christiana. Si Groult y Kerremans confirman que es desde 1557 cuando se pierde la documentación de la Universidad de Lovaina, esto justificaría un inicio de sus estudios en ese mismo año, como muy pronto.

4. Al regresar a Amberes de sus estudios en la Universidad de Lovaina, entró en contacto con Francisco de Soria, un caballero de Logroño, con quien viajó durante un año y a quien dedicó su traducción de Eutropio en 1561:

Estando pues en este tiempo en Anuers, enfermo un cauallero de Logroño llamado fr. ${ }^{\text {co }}$ de soria y como viessen los médicos, que su enfermedad era toda de melancolia, y ymaginacion, de la qual no hay que dar cuenta porque era toda persuassion sola, fuele aconsejado que se saliesse a desbaar aquellos pensamientos y a passear por de fuera por aquellas tierras, pues era el mayo, y tiempo por allí muy fresco y apazible, y que pues tenia buscarse una compañia con quien se diuirtiesse, y como le dixessen de mi, que era todo lo que el podia dessear, entreueniendo muchos amigos para que lo uuiesse de emprehender, no pude descabullirme, aunque lo quisiera harto, ni librarme en ninguna manera (Martí Grajales, 1927: 148).

Este viaje se produjo entre mayo de un año y del siguiente, de manera que duró unos doce meses ${ }^{38}$. No es baladí para los objetivos de este trabajo delimitar la fecha exacta de este viaje, enmarcado, de un lado, por su regreso a Am-

36 "Y estando en Anuers solicitado por letras de mi padre no lo pude hazer por entonces, sino que despues de auer estado en Anuers por acabar todas estas cosas, me torne a louayna y tuue dos vezes conclusiones en leyes sobre la instituta, y me torne en Anuers acabado que uue en louayna, adonde estuue algunos días" (Martí Grajales, 1927: 150).

${ }^{37}$ El nuevo monarca siguió siendo objeto de los asedios del rey francés, a los que se unió la figura del Papa y, sólo ante esto, para recabar apoyo del reino del que todavía era monarca consorte, volvió a Inglaterra. El 10 de agosto de 1557 se libró la batalla la batalla de San Quintín, que, con la ayuda inglesa, ganó la corona española frente a los franceses, aunque no se firmó la paz con Francia hasta el verano de 1558.

38 "Y como y le uuiesse acompañado todo un año entero de Mayo hasta mayo, viendo que estaua de su humor muy aliuiado y bueno, pedile licencia para tornarme alli a Anuers" (Martí Grajales, 1927: 150). 
beres tras sus estudios en Lovaina ${ }^{39}, \mathrm{y}$, de otro, por la publicación de su traducción de Eutropio. Para ello, uno de los principales argumentos con el que contamos es el itinerario del viaje de Soria y Cordero, que intentaré establecer a partir de algunos datos concretos de las memorias de este último.

Sabemos que partieron de Amberes y que su primera parada fue la casa de reposo del entonces Obispo de Arras, donde parece que sólo estuvieron dos días y, de allí, marcharon a Bruselas, a Gante y, finalmente, a Brujas, "adonde nos detuuimos algunos meses, y todo aquel ynuierno fuymos huespedes de un principal mercader llamado Juan de Matança, y tratados como es razon creer de hombre tan principal, y alli nos entretuuimos alguna parte del verano, y casi todo el ynuierno con las amistades de muchos señores" (Martí Grajales, 1927: 148). Fue aquí, por lo tanto, donde pasaron Soria y Cordero buena parte de ese viaje, desde mediados del verano hasta casi finalizado el invierno, para emprender camino a Francia: llegaron a París, Ruán y Haura de Gracia. De allí fueron a Calais, regresaron a París y volvieron "poco a poco a flandes" (Martí Grajales, 1927: 150). Pasaron por Spa, en la región de Lieja, interesado Soria en sus famosas fuentes termales y medicinales, ya desde época romana aprovechadas como baños.

Tras esa estancia en Lieja, cuya duración no podemos delimitar, Francisco de Soria decidió quedarse allí y Juan Martín Cordero regresó a Amberes, donde debió de traducir la Historia de Roma de Eutropio [n ${ }^{\circ}$ 407] y dedicarla a Soria. Antes de producirse este episodio, Juan Martín Cordero no tuvo tiempo de imprimir su Eutropio, ni mucho menos hubiera sido lógico dedicarlo a Francisco de Soria, por lo que, sin duda, considero la fecha de esta impresión, 1561, como un terminus ante quem para el viaje de Cordero. El hecho de que salieran de las prensas de la viuda de Nucio no es casualidad: todas las obras que Cordero manda imprimir por voluntad propia y no por encargo, salen de este taller, lo que demuestra su indudable relación de cercanía y familiaridad con los $\mathrm{Nu}-$ cio. Este matiz es fundamental para entender la publicación de otras dos obras inmediatamente anteriores por impresores diferentes de Amberes: en 1559 edita con Juan Bellero un pequeño opúsculo de catorce folios llamado Tratado breve de las fuentes azedas que nacen alrededor de la selva de Ardueña y principalmente de la del lugar llamado vulgarmente Espá, que es la fuente que suelen dezir de Lieja de Gilberto Fuchs o Gilberto Limborgh [n ${ }^{\circ} 484$ ] y en 1560 con Egidio Copenio Los vivos retratos de todos los Emperadores de Golzio [ $\mathrm{n}^{\circ}$ 505].

Ambas traducciones son fruto de sendos encargos y su relación con los impresores Bellero y Copenio no fue directa. El Tratado breve de las fuentes aze-

\footnotetext{
${ }^{39}$ Aparentemente, porque es cierto que son esas referencias cronológicas ambiguas que no siempre son ciertas en las memorias de Cordero, al volver de Lovaina sólo estuvo en Amberes unos días antes de ser convencido para viajar con Francisco de Soria.
} 
das contiene un privilegio real fechado en Bruselas el 13 de abril de 1559 y entregado al pintor Gil Pierrirs para que "él sólo o quien su poder oviere imprima, venda y distribuya por todos sus estados y señoríos cierto tratado de medicina intitulado De acidis fontibus Arduennae [...] en qualquier lengua que sea" 40 . De hecho, él mismo es quien traduce la obra al francés, que se publica en aquel año en las prensas de Bellero, como la traducción castellana de Cordero y el original en latín. Esta obra nos habla de la fuente de Lieja a la que fueron el valenciano y Francisco de Soria, cuya agua "tiene propiedades para muchas enfermedades, y particularmente para las quartanas, obstructiones, para los dolores de hijada, para las tercianas, para el mal de piedra, segun va en un librillo compuesto por mi el qual hize alli, y se imprimio en Anuers" (Martí Grajales, 1927: 150). Si fuese cierto lo que dice Cordero en sus Memorias, será en Lieja donde tradujo esta obra, durante su estancia en Spa con Soria, lo que nos habría aportado otro terminus ante quem para el fin de su viaje, que hubiese sido el año 1559.

5. Si tenemos en cuenta los datos fehacientes de los impresos y los analizamos en paralelo a lo que sabemos de su biografía, Juan Martín Cordero no dejó de colaborar con la oficina de Nucio hasta primavera o verano de 1557 - lo que, además, es coherente con la pérdida de documentación en esa Universidad a partir de este año y el silencio documental respecto a Cordero- y no regresó antes de la primavera de 1559. Creo que son estas las fechas más factibles porque, por un lado, se interrumpe en 1557 su colaboración con Nucio y, por otro lado, un regreso a Amberes en 1560 tras su estancia universitaria en Lovaina complica y acelera la cronología de los hechos para dar lugar a la impresión de su Eutropio en 1561. Si Cordero estuvo los primeros meses de 1557 en Amberes y marchó a Lovaina entre la primavera de este año y la de 1558, y, paralelamente, consideramos que allí cursó dos años de leyes, se concluye que la fecha en que regresó a Amberes y en que conoció a Soria fue en la primavera de 1559 o 1560. Si optásemos por la hipótesis de las fechas más tardías, tendríamos que Juan Martín Cordero habría regresado de su viaje con Soria en mayo de 1561, cuando, en realidad, la fecha de la dedicatoria está datada con anterioridad: en Amberes el 10 de marzo de este año. De todo esto se concluye claramente que el regreso del viaje por Flandes y Francia fue en mayo o junio de 1560, con tiempo para traducir su Eutropio, que dedicó a su amigo Soria a principios de marzo del año siguiente, fecha en que, lógicamente, debía de estar acabado el trabajo $^{41}$. De esto se deriva, consecuente y retroactivamente, que su vuelta de

\footnotetext{
${ }^{40}$ La transcripción es mía.

${ }^{41}$ De hecho, mantuvo el contacto con Soria, al que fue a ver a Bruselas un tiempo después de haberse separado de él en Lieja, quizás para llevarle un ejemplar de esta traducción, como hizo con la mismísima María Tudor respecto de la Cristiada.
} 
Lovaina a Amberes fue en mayo de 1559 y que su marcha fue en 1557, probablemente hacia la primavera.

Sin embargo, hay un dato que parece negar esta hipótesis cronológica, pero que no es sino fruto de una contradicción de las memorias de Cordero. El 1559 sale a la luz en Amberes la traducción que hizo Cordero del tratado de Gilberto Fuchs sobre los beneficios de las aguas de la fuente de Spa, del que nos dice explícitamente el valenciano que fue "compuesto por mi el qual hize alli, y se imprimio en Anuers" (Martí Grajales, 1927: 150). Si allí es Lieja, ésta fue la última parada de su viaje en común con Soria, hecho que nos permitiría localizar el final de éste en unas fechas cercanas a la primavera de 1559. Esto, sin embargo, no fue posible si damos validez a otro dato que aporta Cordero: la duración del viaje entre los meses de mayo de dos años diferentes. No creo que podamos dudar de las fechas que lo sitúan en la Universidad de Lovaina, porque parten de unos documentos concretos que no tendrían por qué falsear su localización. Por lo tanto, es seguro que entre el 15 de mayo y el 8 de septiembre de 1558, Juan Martín Cordero fue estudiante en Lovaina y allí residió, por lo que es imposible datar el inicio de su viaje con Soria en mayo de 1558.

No tengo la menor duda de que el dato inexacto de las memorias de Cordero es el contexto de su traducción del Tratado breve, que no fue en Lieja, porque se contradice con otras informaciones aportadas por él mismo, porque no es coherente con el resto de la cronología establecida y porque esta traducción debe de estar relacionada con la de Golzio, que imprimió un año después. No debió de ser casualidad que tras entrar en contacto con el pintor Gil Pierrirs, poseedor del privilegio para imprimir el tratado De acidis fontibus Arduennae en cualquier lengua, Cordero tradujese el texto de Los vivos retratos de todos los Emperadores, obra de Humberto Golzio, otro pintor flamenco.

Aunque Peeters Fontainas localiza la traducción de Golzio cuando Cordero era estudiante en Lovaina ${ }^{42}$, creo que no fue así. No puede pasarnos desapercibido otro dato de sus memorias como su estancia prolongada en Brujas muy al principio del viaje, "adonde nos detuvimos algunos meses, y todo aquel ynuierno fuymos huespedes de un principal mercader llamado Juan de Matança, y tratados como es razon creer de hombre tan principal, y alli nos entretuuimos alguna parte del verano, y casi todo el ynuierno con las amistades de muchos señores" (Martí Grajales, 1927: 148), unos señores a los que pasó a ver al final de su viaje, tras dejar a Soria en Lieja y antes de volver a Amberes: "me vine a Brujas, a despedirme de aquellos señores, de quienes yo auia recebido tantos fauores y mercedes" (Martí Grajales, 1927: 150). Humberto Golzio se encontraba en Brujas por aquella época, protegido por el famoso mecenas Marcus

42 "La traduction du texte en espagnol est due à Juan Martin Cordero, de Valence, alors étudiant à Louvain” (Peeters Fontainas, 1965: 266). 
Laurinus, que fue cercano a Erasmo. Dudo mucho de que esto sea una casualidad y me inclino a pensar que esta obra se tradujo en Brujas, aunque Los vivos retratos de todos los Emperadores se imprimieran - probablemente, por la dificultad de edición, dado el amplio número de grabados - un tiempo después en Amberes, sin necesidad de estar él presente. Por aquellas mismas fechas y en aquel mismo contexto, Gil Pierrirs, que había traducido al francés la obra de Fusch, entró en contacto con Cordero y le propuso la traducción castellana, encargo que debió de cumplir con rapidez, por lo breve del texto, y que salió en aquel mismo año de 1559 en Amberes. El interés por la fuente de Spa y sus propiedades curativas por parte de Cordero y Soria debió de derivarse de esta traducción, cuya noticia les llegó al inicio del viaje, que prosiguieron mientras que el beneficiario del privilegio llevó a Amberes la obra para ser impresa.

6. La relación de Juan Martín Cordero con el Cancionero general de 1557 se basa en silogismos sencillos, pero muy débiles argumentativamente: si este humanista trabajó por aquella época como corrector en el taller de su impresor, si las novedades añadidas a esta antología clásica giran alrededor de la boda del entonces príncipe Felipe con María Tudor y si Cordero asistió a esa boda, entonces, habría que pensar que, como concluyeron Peeters Fontainas y Rodríguez-Moñino, “debajo de la edición del Cancionero está el andariego humanista valenciano" (González Cuenca, 2004, I: 7443). Sin embargo, las posibles correcciones tipográficas y lingüísticas de esta obra poco tienen que ver con los otros encargos de Nucio.

Cordero, dedicó a la reina María su traducción de la Cristiada de Jerónimo Vida, que acababa de imprimir Martín Nucio en Amberes, con la firme voluntad de asistir a la boda de Felipe de Austria y de María Tudor y de entregárselo en persona. Llegó a Londres, por lo tanto, unas semanas antes del 25 de julio de 1554, fecha de la boda de Felipe con la reina María, a la que asistió, y se marchó el 18 de noviembre de ese mismo año, en dirección al puerto de Amberes, donde llegó en la víspera del día de santa Catalina de Alejandría, es decir, seis días después, el 24 de noviembre de $1554^{44}$. Tuvo la suerte de que, tras un primer intento fallido de llegar a Inglaterra, optó por cruzar el Canal de la Mancha por Calais y allí se encontró con un embajador de Carlos V y con el

43 "En otra dirección, pero también con innegable aplicación de criterios de grupo, en las ediciones de Amberes se detecta la mano de colaboradores del impresor Nucio, como la del valenciano Juan-Martín Cordero, sobre todo en el bloque de los poemas que se hicieron con motivo de la boda londinense de Felipe II y su tía María Tudor" (González Cuenca, 2004, I: 61).

44 "Tres o quatro compañeros concertamos de nos venir, y assi nos embarcamos con una chaoma en Londres que venia cargada de toneles de cerueza, que suele ser harto mejor que la serueza que en flandes se beue, y tambien mas cara. Y assi nos embarcamos a los 18 de Noviembre[...]. Vispera de la bendita S. ${ }^{\text {ta }}$ Catharina llegamos a Anuers" (Martí Grajales, 1927: 147). 
alcalde de corte Birbiesca, enviados por el Emperador para atajar posibles disturbios derivados de los círculos cercanos al Príncipe, que no aceptaban de buen grado la unión ${ }^{45}$. Este embajador Coureiras no era el ordinario establecido en Londres, ante el cual intercedió Cordero para entregar su libro a la reina María $^{46}$. Por estas fechas, todavía no se encontraba el príncipe Felipe en Inglaterra y Juan Martín tuvo la oportunidad de asistir a su fastuoso recibimiento ${ }^{47}$, que era uno de sus objetivos desde un principio, con ansia de conocer esa corte que lo acompañaba ${ }^{48}$. Así fue, de hecho, y llegó a entablar relación con:

los principales señores de España, con quienes y a quienes yo me di a conocer con mis pocas habilidades. Tomé amistad con el conde de Feria, con el de Oliuares que me quiso tomar por maestro de dos hijos que alli tenia, y con el marques de Sarria, y con don Pedro de Castro obispo de Salamanca, y capellan mayor del Rey, y tome gran amistad con el duque de Medinaceli, y con el marques de Aguilar, y con el duque viejo de Alba don fernando de Toledo, y muy grande con don Aluaro de Sandi el viejo, y con el conde de fuensalida que tambien quiso tomarme en su casa, que es de los Ayalas, y con muchos otros, y pudiera ser que si quisiera seguir corte, pudiera adelantarme algo mas, y pudiera ser que hoy fuera otro de mi (Martí Grajales, 1927: 147).

Tuvo la oportunidad de reencontrarse con buena parte de ellos en Flandes en agosto de 1555, con la llegada de Felipe II para tomar posesión del Imperio. Allí, sus relaciones con la corte están atestiguadas por él mismo: protegido del Obispo de Arras y buen amigo del Duque de Sessa, personajes clave durante el reinado de Felipe II y muy cercanos al monarca.

45 "En este mismo dia llego alli un embaxador del Emperador llamado mosr. de Curiera con un alcalde de corte llamado el Alcalde do Birbiesca, y el Emperador embiaua a los dos, al de Curiera por embaxador, del parabien del casamiento firmado entre el principe y la Reyna Maria; aunque auia alli otro embaxador el ordinario, el qual llamauan Mosr. Reuarte. Embiaua el Emperador al Bribiesca para que tuuiesse muy en seso a los Españoles que alli estauan muy en seso (sic), y sin discordia, porque segun la gente auia tomado mal las amistades y casamiento hecho y pactado de la Reyna y el principe don felipe, no fuessen causa que pues estaua todo apaciguado, re reboluiesse algo, por donde viniesse a ser peor lo postero que no auia sido lo primero" (Martí Grajales, 1927: 145).

46 "Y alli con el $\mathrm{S}^{\text {or. }}$ de Courieras, y me prometio de hazerme todo fauor contra el Embaxador, y confiado en su palabra nos embarcamos todos a las nueue del dia, y a la tarde passamos aquel estrecho" (Martí Grajales, 1927: 145).

47 "Tuuo alli el rey al desembarcar una acanea muy hermosa guarnecida toda de oro, y plata, encubertada muy ricamente, mando que todo el seruicio fuesse de yngleses, y luego se vino para vucestre, y dia de Santiago se velo en publico, y derecho caminando se vino poco a poco a Londres, adonde le tenian aparejada muy solene entrada, y estaua londres muy hornado de vanderas espectaculos y arcos triunfales" (Martí Grajales, 1927: 146).

48 Sabemos que su corte los siguió de Londres a Hampton Court: "Auiendose holgado y detenido en Londres algun tiempo, determinaron los Reyes yrse a holgar a la casa de Amtoncurt, y assi toda la corte uuo de yr alla" (Martí Grajales, 1927: 147). 
Durante su trabajo en el taller de Nucio, tuvo la oportunidad de acercarse a los principales humanistas de la corte filipina, erasmistas la mayor parte de ellos, impulsados por el mecenazgo de algunos de los nobles cortesanos que acompañaban al Rey o por él mismo. En este contexto y claramente derivado de su contacto con la corte filipina, Cordero tradujo dos opúsculos de Erasmo y otro de Vives. Éste fue su papel en el taller de Nucio, el de humanista corrector de traducciones, a quien no se le conoce ningún interés explícito por la poesía de cancionero, más que una composición de autoría propia sobre el incendio de la iglesia de Santa Catalina de Valencia, bastante posterior. He demostrado que no pudo haber contribuido al proyecto editorial del Cancionero de romances, por lo imposible de las fechas, y no creo tampoco que Cordero tuviera ningún interés preconcebido por el Cancionero general.

Aunque no al nivel que describe para sí Juan Martín Cordero, Martín Nucio también tenía contacto con algunos miembros de la corte filipina desde su anterior visita. Asimismo, ha demostrado un interés claro por las recopilaciones de poesía, tanto por los romances, como por la lírica: desde su importantísimo Cancionero de romances ([1547-1548] [ $\left.\mathrm{n}^{\mathrm{o}} 177\right], 1550\left[\mathrm{n}^{\mathrm{o}} 178\right]$ y $1555\left[\mathrm{n}^{\mathrm{o}}\right.$ 179]), hasta su Cancionero general de 1557, pasando por sus impresiones de Juan de Mena (1552) [ $\mathrm{n}^{\circ}$ 774], de Boscán y Garcilaso (1544) [ ${ }^{\circ}$ 144], [1545] [n $\mathrm{n}^{\mathrm{o}}$ 145], [1546-1547] [ $\left.\mathrm{n}^{\circ} 146\right],[1550]\left[\mathrm{n}^{\circ} 147\right]$ y $\left.1556\left[\mathrm{n}^{\circ} 149\right]\right)$ y de los Romances de Lorenzo de Sepúlveda (1551) [ $\mathrm{n}^{\circ}$ 1186]. Este impresor tenía una clara intuición editorial y una trayectoria que justifica que la empresa de editar el Cancionero general fue una decisión propia.

El Cancionero general nació con prisas e improvisación (Martos, 2010b), en la línea del Cancionero de romances de Lorenzo de Sepúlveda que imprimió Steelsio: Nucio quiso sacar su Cancionero general con rapidez, a fin de que ningún otro impresor se le adelantara en tal novedad antuerpiense. Sin embargo, cuando estaba prácticamente en prensas, se añadieron al final del volumen algunas composiciones, relacionadas la mayoría de ellas con la boda del príncipe Felipe y María Tudor. Juan Martín Cordero, cercano a algunas de las principales figuras de la corte hispano-flamenca de Felipe II y habiendo estado en la boda de la que trataban muchos de los poemas, sí que pudo tener acceso a este cancionerillo y, teniendo en cuenta la voluntad de Nucio por imprimir el Cancionero general, que respondía en cierta medida al intento de aprovechar el mercado que significaba la estancia de la corte española en Flandes, pudo servir de enlace para su inclusión a efectos comerciales. Hasta aquí pudo llegar una posible intervención de Juan Martín Cordero en la edición del Cancionero general de 1557: proporcionar al impresor de la antología unas novedades poéticas que pudieran despertar un interés mayor por este cancionero clásico y diferenciarlo, así, de ediciones anteriores o posteriores. Si esto fue así, sin embargo, no podemos descartar que sí que se involucrara como corrector lingüístico 
y tipográfico del impreso, al menos parcialmente y por lo que respecta a esta última sección, pero esto es algo que no tenemos documentado, a diferencia de lo que ocurre con las traducciones humanistas que salieron del taller de Nucio. En definitiva y por lo tanto, este dato sería suficiente para relativizar su participación en el proyecto de edición del Cancionero general de 1557, por inexistente o por insignificante cualitativa o cuantitativamente.

\section{BIBLIOGRAFÍA}

Bataillon, Marcel (1966 [1950]): Erasmo y España. Estudios sobre la historia espiritual del siglo $X V I, 2^{\mathrm{a}}$ ed., México-Buenos Aires, Fondo de Cultura Económica.

Bonilla y San Martín, Adolfo (1907): "Erasmo en España. Episodio de la historia del Renacimiento", Revue Hispanique, 17, pp. 379-548.

Carlos Morales, Carlos Javier de (1994a): "El poder de los secretarios reales: Francisco de Eraso", en José Martínez Millán (ed.), La corte de Felipe II, Madrid, Alianza Universidad, pp. 107-148.

Carlos Morales, Carlos Javier de (1994b): "Ambiciones y comportamiento de los hombres de negocios. El asentista Melchor de Herrera”, en José Martínez Millán (ed.), La corte de Felipe II, Madrid, Alianza Universidad, pp. 379-415.

Escartí, Vicent Josep (1997): La primera edició valenciana de l'obra d'Ausiàs March 1539, 2 vols., València, Bancaixa/Universitat de València/Generalitat Valenciana/Biblioteca Nacional.

Gonzalo Sánchez-Molero, José Luis (1997): El erasmismo y la educación de Felipe II (15271557), tesis doctoral, Madrid, Universidad Complutense de Madrid.

Groult, Pierre (1958): "Juan Martín Cordero en los Países Bajos", en Actas del III Congreso de Cooperación Intelectual (Cáceres, 1958), Madrid, Instituto de Cultura Hispánica, pp. 1-3.

Groult, Pierre (1962): "Escritores españoles del siglo XVI en los Países Bajos", Actas del I Congreso de la Asociación Internacional de Hispanistas, pp. 87-105.

Hernando del Castillo (2004): Cancionero general, Joaquín González Cuenca (ed.), 5 vols., Madrid, Castalia.

Herrán Martínez de San Vicente, Ainara (2008): "El mecenazgo de los jerarcas eclesiásticos en la época de los Reyes Católicos", en Nicasio Salvador, Miguel y Cristina Moya García (eds.), La literatura en la época de los Reyes Católicos, Madrid/Frankfurt am Main, Universidad de Navarra/Iberoamericana-Vervuert, pp. 79-101.

Martí Grajales, Francisco (1927): Ensayo de un diccionario biográfico y bibliográfico de los poetas que florecieron en el Reino de Valencia hasta el año 1700, Madrid, tip. de la Revista de archivos, Bibliotecas y Museos.

Martos, Josep Lluís (2010a): "El público de Martín Nucio: del Cancionero de romances al Cancionero general de 1557”, en Vicenç Beltran y Juan Paredes (eds.), Convivio. Cancioneros peninsulares, Granada, Universidad de Granada, pp. 111-123.

Martos, Josep Lluís (2010b): "La autocensura en los cancioneros: una justificación impresa en 57CG y otra manuscrita en CT1", Cultura Neolatina, LXX, 1-2, pp. 155-180.

Núñez Bespalova, Marina (2008): "El mecenazgo nobiliario en la literatura de la época de los Reyes Católicos. Primera aproximación", en Nicasio Salvador Miguel y Cristina Moya García (eds.), La literatura en la época de los Reyes Católicos, Madrid/Frankfurt am Main, Universidad de Navarra/Iberoamericana-Vervuert, pp. 167-188.

Peeters Fontainas, Jean F. (1953): "Extrait des Mémoires de Jean-Martin Cordero de Valence. Sa vie d'étudiant à Louvain; ses traductions espagnoles; ses éditions aux Pays-Bas", De Gulden Passer, 31, pp. 59-87. 
Peeters Fontainas, Jean F. (1965): Bibliographie des Impressions Espagnoles des Pays-Bas Méridionaux, 2 vols., Nieuwkoop, B. de Graf.

Rivero Rodríguez, Manuel (1994): "El servicio a dos cortes: Marco Antonio Colonna, almirante pontificio y vasallo de la monarquía", en José Martínez Millán (ed.), La corte de Felipe II, Madrid, Alianza Universidad, pp. 305-378.

Rodríguez-Moñino, Antonio (1965): "Semblanza del autor", en J. F. Peeters Fontainas, Bibliographie des Impressions Espagnoles des Pays-Bas Méridionaux, 2 vols., Nieuwkoop, B. de Graf, pp. IX-XXII.

Rodríguez-Moñino, Antonio (ed.) (1967): Cancionero de romances (Anvers, 1550), Madrid, Castalia.

Salvador Miguel, Nicasio (2008): Isabel la Católica. Educación, mecenazgo y entorno literario, Alcalá de Henares, Centro de Estudios Cervantinos.

Voet, Leon (1969-1972): The Golden Compasses. The History of the House of Plantin-Moretus, 2 vols., Amsterdam/London-New York, Vangendt \& Co./Routledge \& Kegan Paul/Abner Schram.

Fecha de recepción: 17 de abril de 2013

Fecha de aceptación: 18 de octubre de 2013 